\title{
Identidades profissionais médicas em disputa: Congresso Nacional dos Práticos, Brasil (1922)
}

\author{
Professional medical identities in contention: \\ The National Practitioners' Congress, \\ Brazil (1922)
}

André de F. Pereira Neto 1

\footnotetext{
1 Departamento de Pesquisa Casa de Oswaldo Cruz, Fundação Oswaldo Cruz. Av. Brasil 4036, sala 401, Rio de Janeiro, $R J$ 21040-361, Brasil pereiraneto@hotmail.com
}

\begin{abstract}
The object of this paper is the debate among the Brazilian medical elite during the National Practitioners' Congress (Congresso Nacional dos Práticos -1922). The article begins by analyzing a specific moment in the medical profession's history in early 20th-century Brazil, specifically Rio de Janeiro's 1922 National Practitioners' Congress. The author presents three profiles of medical practice observed in that context: generalists, specialists, and hygienists. He further analyzes their characteristics, similarities, and differences, as well as the strategies for professional affirmation adopted by physicians with these profiles. The article addresses the following issues: What were the relationships between the specialization process, forms of remuneration, and the construction of new professional identities? What identities did medical doctors create for themselves? What were the rivalries between these different professional identities? How did they portray outside competitors, such as the so-called traditional healers? Finally, the author presents several methodological suggestions that may contribute to historical research on the medical profession.
\end{abstract}

Key words Health Occupations; Social Identification; History of Medicine

Resumo O objeto deste artigo é o debate travado entre a elite médica brasileira durante o Congresso Nacional dos Práticos, realizado no Rio de Janeiro em 1922. Inicialmente apresentamos o conceito profissão do ponto de vista sociológico. Em seguida analisamos um momento da História da profissão médica no Brasil: o início do século XX, em particular, o Congresso Nacional dos Práticos. Apresentamos os três perfis de prática médica observados naquele contexto, a saber: Generalista, Especialista e Higienista. Analisamos suas características, semelhanças e diferenças, bem como as estratégias de afirmação encetadas por cada identidade profissional. As questões que orientaram este trabalho foram as seguintes: Que relações foram estabelecidas entre o processo de especialização e de assalariamento e a construção de novas identidades profissionais? Quais as identidades que os médicos inventaram de si? Que rivalidades foram sendo construídas entre estas diferentes identidades profissionais? Como eles representavam os concorrentes externos, tais como os curandeiros? Finalmente apresentamos algumas sugestões metodológicas que poderão ser aproveitadas em estudos históricos cujo objeto preferencial de análise seja a profissão.

Palavras-chave Ocupação em Saúde; Identificação Social; História da Medicina 
O tema geral deste artigo é a identidade profissional médica. Quando usamos o conceito profissão, amparamo-nos sobretudo em alguns autores norte americanos, tais como Freidson (1970), Larson (1977) e Abbott (1988), da mesma forma que em franceses, como Leonard (1978), Goubert (1992), Herzlich (1982) e Guillaume (1996), os quais definem a profissão como ocupação com prestígio e poder especial.

A profissão diferencia-se da ocupação em razão de chegar a adquirir, por meios políticos, culturais e ideológicos, extraordinária autoridade cognitiva e normativa. A atividade profissional, do ponto de vista cognitivo, deve deter pelo menos três características: ser complexa e incompreensível por leigos; ser institucionalizada em estabelecimentos de ensino e ser aplicável, de modo a resolver problemas tidos como relevantes pela sociedade. Deste modo, o profissional satisfaz a primeira condição - necessária, mas não suficiente - para reivindicar exclusiva jurisdição acerca de determinada atividade.

Do ponto de vista normativo, o profissional deve submeter-se a longo treinamento, orientado por currículo padronizado, repleto de etapas e exigências. Durante o período universitário e ao longo de toda a sua atividade, deve sujeitar-se aos mecanismos de regulação de conduta, formalizado em um Código de Ética, relativo a seus pares, a seus concorrentes e a seus clientes. Em geral, as demais atividades do mundo do trabalho prescindem de um código formal que as regule e que padronize sua conduta. Tal dimensão normativa faz com que as profissões se tornem comunidades com identidade, compromisso pessoal, interesses específicos e lealdade corporativa, permitindo que conquistem, assim, prestígio junto à clientela.

Para Machado (1996), o exercício da atividade do profissional no mercado de trabalho deve desenvolver-se com ampla autonomia econômica e técnica. A autonomia econômica permite que o profissional tenha liberdade de atuar em sua esfera exclusiva de competência. Por sua vez, a dimensão técnica da autonomia pressupõe, no entender de Schraiber (1993), que o profissional seja capaz de invalidar o serviço do leigo, comprometendo-se com a organização de efetivo controle de admissão.

Além disso, segundo Starr (1982), o profissional deve empreender todo um conjunto de estratégias de persuasão voltadas aos clientes, para que estes se submetam à sua autoridade cultural. Para tanto, o consumidor de serviços deve ser alguém nem muito organizado socialmente nem muito informado, assim ele receberá as determinações do profissional sem con- testação. Desta forma, a orientação do profissional passa a ser entendida pelo cliente como algo superior a um conselho e inferior a uma ordem. Com o intuito de atingir essa situação, o profissional utiliza-se de meios simbólicos.

A literatura especializada enfatiza ainda a necessidade de serem levadas em consideração as especificidades de cada atividade profissional. No caso, a profissão médica apresenta particularidades que precisam ser ressaltadas.

O médico entra em contato íntimo e direto com a vida privada de seu cliente. Ele participa de momentos cruciais dessa existência, servindo de intermediário entre o saber generalizante e o caso particular. As circunstâncias da doença promovem a aceitação de seu julgamento. Um dos fatores que explicam o sucesso da medicina está associado ao poder que esta profissão tem de fomentar a dependência do cliente no que diz respeito ao conhecimento e à competência do médico. Esta dependência é construída ideologicamente ao longo de um processo histórico.

Neste artigo, não analisaremos um longo período histórico. Concentraremos nossa atenção no contexto brasileiro do início do século XX. Examinaremos especificamente os anais do Congresso Nacional dos Práticos, realizado no Rio de Janeiro em 1922. O momento em que este evento foi efetuado, os atores que estiveram presentes e os temas que foram debatidos justificam a escolha de tal objeto empírico (Pereira Neto, 1997).

Até o princípio do século XX predominava, no Brasil, o exercício profissional em bases liberais: o médico dependia de capacidade própria para exercer sua atividade. Tinha autonomia para determinar as condições e o valor de seu trabalho. Além disso, o conhecimento médico entendia o corpo humano como um todo indivisível. A habilidade e a sensibilidade eram os principais atributos do médico. O conhecimento era obtido com anos de experiência prática. Contudo, a partir do início do século XX começaram a ocorrer, no Brasil, alterações na base do conhecimento médico e nas políticas públicas da área da saúde que interferiram em semelhante identidade profissional hegemônica.

O processo de especialização, observável em outras atividades no mundo do trabalho, fez com que o conhecimento médico passasse a ser organizado segundo a área do corpo ou o tratamento de doenças específicas. O trabalho médico começou a assumir um caráter parcelar, promovendo práticas interdependentes, solidárias e coletivas, pois requeriam a intervenção de vários profissionais. Além disso, a incorporação de forte arsenal tecnológico permitiu 
que o diagnóstico se tornasse cada vez mais preciso, aumentando os custos da produção do serviço, como enfatizou Donnangelo (1975).

Ao mesmo tempo, o Estado brasileiro deu início ao abandono da postura liberal que adotara, até então, frente à problemática social. A esse respeito, Luz (1982) expôs como a questão social começou a deixar de ser vista como coisa de polícia para tornar-se questão política. $\mathrm{O}$ Estado passou a assumir, aos poucos, o papel de gerente e produtor de serviços em diversas áreas, sobretudo na saúde. Através de um processo lento e progressivo, pleno de ações e reações, pôde ser observada tal mudança de postura. Um sinal neste sentido pode ser identificado, em 1920, na criação do Departamento Nacional de Saúde Pública (DNSP), primeira organização estatal de dimensões nacionais que contava com estrutura hierarquizada e burocratizada. Sua finalidade era atingir desde a medicina preventiva e a curativa até a engenharia sanitária. $\mathrm{O}$ incremento da presença do Estado na área da saúde guardava expressivo potencial de promover o assalariamento médico, fundando, por sua vez, esferas públicas de atuação profissional com visíveis conotações políticas. Além disso, facultava os serviços das instituições públicas ao cliente tradicionalmente atendido em consultórios particulares.

No Congresso Nacional dos Práticos, médicos brasileiros eruditos e famosos reuniram-se para discutir o que deveria ser feito diante destas virtuais modificações. Entre eles encontravam-se cidadãos detentores de riqueza, respeitabilidade e conhecimentos e que ocupavam postos de direção no Estado ou em instituições da sociedade. Alguns tinham perfil mais clínico, enquanto outros dirigiam instituições responsáveis por elaborar políticas higiênicas de longo alcance. Os dados biográficos permitem concluir que o Congresso Nacional dos Práticos reuniu a elite médica brasileira da década de 1920, tal como no caso francês analisado por Weisz (1988).

A Sociedade de Medicina e Cirurgia do Rio de Janeiro havia organizado oito congressos médicos no período compreendido entre 1888 e 1922. O Congresso Nacional dos Práticos não foi, assim, a primeira reunião de médicos brasileiros. O que o diferenciou dos eventos anteriores? Lendo e analisando os anais dos congressos médicos anteriores a 1922, podemos constatar que predominavam ora os temas que geravam curiosidade científica ora os debates a respeito das estratégias públicas de profilaxia das doenças infecto-contagiosas. O Congresso Nacional dos Práticos assumiu sua especificidade em relação aos congressos médicos ante- riores em virtude de, nele, terem sido aceitos apenas os trabalhos que diziam respeito ao exercício e ao ensino da medicina, conforme rege seu Regulamento (1918). O evento transcorreu como em um palco em que a elite médica divergiu quanto às estratégias de preservação de seu prestígio, autoridade e autonomia. Na platéia estavam presentes representantes do poder executivo e legislativo, de sociedades científicas, de associações profissionais e de faculdades de medicina.

A expectativa dos organizadores era de intervir no curso do acontecimentos. O Congresso Nacional dos Práticos realizou-se na cidade do Rio de Janeiro, então capital da República, entre os dias 30 de setembro e 7 de outubro de 1922, ou seja, um mês e meio antes da investidura de Artur Bernardes como Presidente da República, eleito em março, em meio a convulsionado processo de sucessão.

Diante dos elementos apresentados acima podemos atestar a importância histórica do evento. Neste trabalho, sua escolha como fonte principal de análise justifica-se pelo fato de as seiscentas e dezenove páginas publicadas em suas Actas e Trabalhos (Primeiro Congresso Nacional dos Práticos, 1923) traduzirem boa parte dos embates e controvérsias profissionais presentes no seio da elite médica durante a Primeira República no Brasil (1889/1930). Nos debates travados identificamos a presença de três perfis de identidade profissional médica: o Generalista, o Especialista e o Higienista. Os dois grandes eixos de tensão existentes entre eles eram os elementos que confrontavam o generalismo à especialização e os que contrapunham a prática em serviços públicos àquela exercida em serviços privados.

O perfil que denominamos generalista caracteriza-se por privilegiar valores próprios à identidade profissional hegemônica no Brasil até o início do século XX. Nesse período, o médico era identificado como produtor individual de serviços, portador de conhecimento abrangente a respeito do doente e da doença. Longe de ser uma ciência, um saber complexo e sistematicamente constituído, a medicina era vista como arte. A relação médico-paciente pautava-se pela intimidade, confiança e obediência. Assim, o médico generalista buscava organizar o cotidiano do cidadão desde seus hábitos de higiene mais íntimos até as intervenções cirúrgicas em que o risco de vida era eminente.

No mercado de trabalho, ele configurava a expressão mais precisa do produtor individual de serviços de saúde: o médico exercia individualmente sua atividade e não contava com auxílio nem de outro médico nem de qualquer 
profissional de saúde. A relação era, portanto, individualizada e direta. Por esta razão, ressaltavam-se os atributos individuais em detrimento de elementos próprios ao trabalho em equipe, em que o profissional se submete a procedimentos racionais ou burocráticos. Além disso, os exames diagnósticos em laboratório eram considerados prescindíveis. Esse tipo de médico examinava, identificava a origem da dor, prescrevia medicamentos e operava, se fosse o caso, sem a ajuda de terceiros ou do aparato tecnológico. Para ele, o mais importante era o contato direto, individualizado e insubstituível com seu paciente. Segundo tais características, a prática médica deveria depender, sobretudo, da sensibilidade e da experiência do profissional adquiridas ao longo de anos de trabalho.

Até o início do século XX, o consultório funcionava, muitas vezes, como um mini-hospital, freqüentemente instalado na residência do próprio médico. Para nós, o médico de perfil generalista era produtor individual de serviços, na medida em que detinha total liberdade de estabelecer o valor, a duração e as condições em que se desenvolveria a consulta: não existia, entre ele e o paciente, qualquer mediação burocrática. Para ele, a autonomia técnica e a econômica estavam garantidas em sua plenitude.

O médico generalista era, portanto, alguém que valorizava mais a arte e a subjetividade em detrimento da racionalidade técnica. Além disso, sua prática estava voltada para o indivíduo e não para as coletividades. Seu padrão ideal de relação com o mercado de trabalho se dava sob a forma liberal em consultório particular e não sob a forma assalariada em estabelecimento público ou privado. Os generalistas, em geral, enfatizavam o lado artístico e altruísta da prática profissional. Como afirmou Meireles (1923:164), quem não seguisse estes princípios não seria "nunca um verdadeiro médico". Desta forma, os generalistas reiteravam valores que deveriam nortear a prática profissional ideal, desqualificando as demais.

No início do século XX, este perfil começava a sofrer lento e constante processo de modificação, conquanto ainda fosse dominante no Brasil. A identificação de uma mencionada cri$s e$ funcionava como estratégia retórica para seu fortalecimento. $\mathrm{O}$ assalariamento médico mesmo que irrisório, se comparado ao mesmo processo observado no pós-30 - era identificado como uma das principais razões da erosão desta prática. Os clientes coletivos, como diziam, iam sendo vistos como vetores de transformação da organização do trabalho médico tanto em relação à amplitude de seu mercado quanto em relação aos níveis de autonomia que passariam a presidir a relação com seu paciente.

A criação do Departamento Nacional de Saúde Pública, em 1920, gerou, neste sentido, uma série de reações relacionadas com as potenciais alterações que esta nova estrutura pública poderia introduzir no mercado de trabalho médico. Dizemos potenciais em razão de o Congresso Nacional dos Práticos ter-se realizado dois anos após a promulgação do Decreto Lei 14.354, de 15 de setembro de 1920, que criara este Departamento (Brasil, 1921). Assim, as modificações apresentadas no texto da lei restringiam-se, até então, ao papel: entre 1920 e 1922 não foram implementadas medidas que alterassem substancialmente o mercado de trabalho médico e a presença do Estado na saúde pública. No que se refere à assistência médica, o artigo 261 do Decreto Lei 14.354 (Brasil, 1921) instituía o isolamento nosocomial ou domiciliário aos doentes portadores de qualquer uma das vinte moléstias sujeitas à notificação compulsória, a saber: febre amarela, peste, cólera, tifo, varíola, difteria, infecção puerperal, oftalmia de recém-nascidos, infecções do grupo tifo-paralítico, lepra, tuberculose, impaludismo, escarlatina, sarampo, disenterias, meningite, paralisia infantil, tracoma, leishmaniose e coqueluche.

Neste artigo analisaremos de que maneira a implementação desta política de assistência médica poderia ou não afetar a organização do mercado de trabalho médico. Esse interesse justifica-se na medida em que a universalização do atendimento, bem como sua gratuidade, teria condições de atrair pacientes com alto poder aquisitivo, tradicionalmente atendidos por médicos particulares ou em estabelecimentos privados de assistência. Nosso objetivo será, sobretudo, compreender como os médicos identificados com o perfil generalista reagiram a esta potencial transformação.

O mesmo Decreto Lei facultava o isolamento domiciliar aos portadores de uma das vinte moléstias citadas que residissem em quarto "arejado e independente, revestido de piso de fácil desinfecção”. Afora isso, exigia-se o pagamento de uma taxa que se destinava ao custeio dos serviços diários de enfermagem sanitária.

Segundo Damazio (1996), predominavam, no Rio de Janeiro do início do século XX, os cortiços, ou seja, habitações populares e coletivas localizadas próximo a estalagens ou cocheiras, onde a insalubridade e a imundície prosperavam. Além disso, o rendimento diário dos operários e a faixa salarial do funcionalismo públi- 
co não garantiam os custos mínimos exigidos, por lei, para o isolamento domiciliar.

Assim, podemos concluir, que o isolamento domiciliar não estava sendo previsto nem para os desempregados e demais trabalhadores informais residentes nos cortiços, nem para aqueles que recebiam baixos salários mensais. A característica da residência e a faixa salarial do paciente impediam que segmentos menos favorecidos socialmente tivessem condições de optar pelo isolamento domiciliar. Esta alternativa ficava restrita às classes privilegiadas. Fora do controle institucional e burocrático de um nosocômio, a autonomia técnica teria melhores condições de vicejar.

No Congresso Nacional dos Práticos, Miguel Couto - um dos mais renomeados médicos generalistas brasileiros do início do século, catedrático da Faculdade de Medicina e Presidente da Academia Nacional de Medicina - defendeu que o internamento no hospital fosse visto como "uma exceção e o tratamento no domicílio a regra" (Couto, 1923:562). No caso do isolamento nosocomial, o Regulamento estabelecia procedimentos que variavam de acordo com a moléstia.

Em relação à cólera, tifo, infecção puerperal, oftalmia, infecções tifo-paratíficas, impaludismo, escarlatina, sarampo, disenterias, meningite, paralisia infantil, tracoma, leishmaniose e coqueluche não constava na lei qualquer valor ou tabela que relacionasse os custos pela internação. No caso da varíola e da tuberculose, a gratuidade restringia-se à prevenção ou ao diagnóstico da moléstia. Depois de confirmado o diagnóstico, não havia menção a como se daria o acesso e a permanência dos pacientes nas instituições nosocomiais públicas. Quanto à febre amarela, lepra e doenças venéreas, a gratuidade limitava-se ao enfermo com baixo poder aquisitivo. Os demais pacientes pagariam taxas estipuladas em tabelas fornecidas pela Saúde Pública.

No início da década de 1920, a extensão da gratuidade no atendimento nosocomial não estava ainda plenamente definida por lei. Os generalistas intervieram neste tema, propondo formalmente a segmentação social do atendimento médico em instituições públicas.

Miguel Couto foi um dos que reiteraram esta idéia, propondo que os hospitais públicos tivessem “... enfermarias gratuitas, pequenas salas para a diária de cinco mil réis e quartos particulares para dez mil réis" (Couto, 1923:563). O paciente deveria comprovar seu nível de renda para poder ser encaminhado a um desses espaços. A lógica que inspirava o posicionamento de Couto era a seguinte: se o paciente tives- se que pagar para ser atendido numa instituição pública, preferiria a clínica particular, onde pagaria igualmente, recebendo, entretanto, tratamento de melhor qualidade. Além disso, se a gratuidade universal fosse eliminada, diminuiria o temor que tomava conta de médicos como Miguel Couto: ver sua clientela fugir para as instituições públicas. Era necessário, portanto, garantir que as pessoas com alto poder aquisitivo não fossem atendidas nas enfermarias gratuitas.

Couto, como os demais generalistas, temia a fraude. Receava que alguém com condições de pagar por esses serviços, fingisse pobreza para não pagar a consulta e o tratamento. Para evitar que isso ocorresse, Couto (1923:563) propôs que fosse realizada uma "sindicância para comprovar ou não a fraude". Finda a sindicância, seria avaliado se o cidadão deveria ressarcir ou não os cofres públicos. Em suma, o intuito dos médicos generalistas era garantir a maior liberdade possível ao médico profissional liberal nos estabelecimentos públicos que seriam construídos e, ao mesmo tempo, desencorajar os cidadãos de posses a freqüentá-los. Este também poderia ter sido o objetivo dos médicos especialistas, que viviam da clínica liberal. No entanto, consideramos ser o hospital o locus privilegiado para o exercício da prática médica especializada, uma vez que o hospital moderno comporta a intervenção de vários profissionais, dispostos hierarquicamente, além de incorporar forte arsenal tecnológico para o diagnóstico e o tratamento.

O perfil de prática profissional que denominamos especialista reiterava a importância da racionalidade científica, da precisão do diagnóstico, postulando o treinamento metódico e sistemático, a observação e a experimentação. Além disso, o trabalho era visto como atividade de equipe. Nesse caso, cada profissional, segundo sua especialidade, deteria sua parcela de responsabilidade no processo de tratamento e cura. Para esta identidade profissional, por um lado, o conhecimento médico deveria ser, ao mesmo tempo, esotérico, inatingível, institucionalizado e aplicável às demandas concretas. Em tal aspecto residia a principal divergência destes médicos com os de perfil generalista. Por outro lado, os especialistas aproximavam-se dos generalistas, pois igualmente centravam o sentido de sua prática profissional no indivíduo. A medicina era, para ambos, uma atividade com fins exclusivamente curativos.

No Congresso Nacional dos Práticos, os especialistas também afirmaram sua identidade, desqualificando as demais concepções de prática profissional. 
O relator mais idoso do Congresso foi Pacífico Pereira, que contava então 76 anos de idade. Sua atuação profissional transcorrera no Estado da Bahia durante o século XIX. Como boa parte dos médicos de seu tempo, combinara a atividade clínica - em ginecologia - com a pesquisa básica - em histologia, anatomia e patologia. Seu prestígio entre a corporação era tão elevado que os relatores presentes conferiram-lhe o título de Praeceptor Brasiliae. Em termos de poder e prestígio públicos, Pacífico Pereira chegara a exercer o cargo de Diretor da Faculdade de Medicina da Bahia, assim como da Saúde Pública Estadual da Bahia.

Em seu discurso, Pereira (1923:526) afirmou: "Ninguém pode negar (...) que não só o médico mas qualquer sábio, em nossos dias, torna-se cada vez mais um especialista, desde que se exige que seja um mestre no ramo restrito que escolheu, e que os gênios universais, especialistas em todos os gêneros, (...) caíram em descrédito". Analisando suas palavras, podemos concluir que a arrogância na defesa de um ideal profissional não foi exclusividade dos defensores do padrão generalista de identidade profissional. "Ninguém pode negar" constitui exercício de retórica e conformou uma estratégia para tentar convencer o conjunto da categoria de que este relator apresentava uma verdade incontestável. Em geral, quando se afirma enfaticamente que "ninguém pode negar" algo, é porque tal questão está sendo negada por alguém. O esforço de sua argumentação teria sido no sentido de retirar qualquer crédito dos especialistas de todos os gêneros, ou seja, do médico clínico, dotado de conhecimento globalizante, como queriam os generalistas.

As palavras de Pacífico Pereira serviam igualmente para reforçar sua visão, favorável ao trabalho especializado, condenando a prática médica clínica generalista. Para os especialistas, o paciente não deveria, nem poderia, desconfiar das prescrições do médico, sobretudo porque este seria o portador da ciência.

Nos anos vinte, o processo de especialização da medicina estava em gestação. A presença de associações de obstetrícia, ginecologia, oftalmologia, otorrinolaringologia, psiquiatria, neurologia, dermatologia, sifiligrafia e pediatria no Congresso Nacional dos Práticos traduzia um dos sintomas de tal processo em termos de organização profissional.

Oswaldo de Oliveira tinha 38 anos de idade em 1922, contava dezoito de formado e já era catedrático de Clínica Médica da Faculdade de Medicina, membro titular da Academia Nacional de Medicina e médico clínico da Santa Casa. Além disso, detinha larga produção científica, sobretudo na área da cardiologia. Analisando as reformas do ensino médico, Oliveira (1923: 403) afirmou: "Invidia medicorum pessima. Assim sendo explica-se o triste e lamentável desprestígio atual da classe médica: os argumentos para descrédito do ensino da faculdade terão recaído sobre os que nela estudaram, sobre os médicos em geral de cuja ciência se duvida, e a cujo valor profissional não se dá grande importância".

Para Oliveira, a confiança recíproca presente na relação criada entre médico e paciente configurava elemento imprescindível para o sucesso da prática médica. Em seu modo de entender, os curandeiros estabeleciam todo o tipo de estratégias para retirar esta confiança, com a finalidade de obter êxito. A invidia em relação ao médico era, segundo este relator, pessima. Duvidar da ciência? Jamais. Discordar do diagnóstico médico? Nunca. Esta explicação traduz a relação de poder que se queria estabelecer entre médico e paciente, bem como a autoridade que os especialistas queriam imputar à ciência médica alopática oficial. A defesa intransigente do primado da ciência serviu, portanto, de argumento contundente dos especialistas contra as práticas exercidas por curandeiros.

As sociedades nativas americanas e as populações oriundas do continente africano exerceram papel decisivo na formação social e cultural brasileira. Nos dois casos predominavam práticas de cura que utilizavam componentes da natureza associados freqüentemente a forte caráter religioso: práticas de cura não reconhecidas pela ciência médica alopática dominante.

As leis em vigor coibiam a ação dos denominados curandeiros, condenando-os ao pagamento de significativas multas ou até à prisão. Nas determinações legais consta ainda que o exercício das práticas de cura deveria ser acompanhado por habilitação formal obtida nas faculdades de medicina. Assim ficava legalmente garantido o monopólio médico neste ramo de atividade. Por sua vez, toda a prática concorrente que fugisse a este padrão deveria ser penalizada.

Para os especialistas, as determinações legais concernentes ao curandeirismo não eram tidas como suficientes. Muitos médicos pediram a palavra no evento para combater o curandeirismo. A estratégia adotada foi construir uma imagem negativa do curandeiro, acompanhada de um movimento simetricamente oposto em relação ao médico alopata, tido como único portador da ciência. Tratava-se de construir, junto à opinião pública e ao Estado, uma imagem negativa do curandeiro. 
Em parte, a estratégia identificada no combate ao curandeirismo foi a de desqualificação. Se os médicos conseguissem convencer a clientela de que o curandeiro era um "ignorante" por não dominar a ciência médica e que o paciente "corria risco de vida" ao ser atendido por ele, talvez os clientes não procurassem mais seus serviços. Outra medida propalada incitava os médicos a delatar os casos de curandeirismo e exigia que o Código Penal tivesse aplicação mais enérgica.

Dois comentários merecem ser feitos quanto à postura dos especialistas em relação à existência do curandeirismo como prática de cura concorrente com a médica.

Em primeiro lugar resgatamos algumas idéias expostas por Starr (1982), nas quais enfatiza a importância das estratégias persuasivas e coercitivas, empreendidas por médicos norte-americanos, visando à consolidação da autoridade cultural. A combinação das duas estratégias parece ter dado o tom da posição dos especialistas, no que se refere aos curandeiros que concorriam com eles no mercado de serviços e de prestígio.

Em segundo lugar cabe recuperar, ainda que brevemente, a história do positivismo no Brasil. Esta filosofia contrapôs-se aos princípios teológicos e metafísicos dominantes na Europa durante os séculos XVIII e XIX. A neutralidade e a objetividade foram alguns dos argumentos utilizados para justificar o primado da razão tida como desinteressada. Inicialmente, a ciência positiva fez-se revolucionária, na medida em que se contrapôs ao universo de valores feudais. Com o passar do tempo tornouse hegemônica na ordem capitalista e imperialista que se implantava. A intervenção desbravadora que o neocolonialismo perpetrou no mundo subdesenvolvido obteve sucesso, entre outras razões, graças a sua associação com a produção de conhecimentos científico, formulado a partir de matriz positivista. Assim, a racionalidade positivista tornou-se cada vez menos neutra e desinteressada, apesar de, formalmente, pretender manter tais características.

No Brasil, enquanto alguns seguidores das teorias de Augusto Comte - presos ao primado da liberdade - pregavam que a atividade profissional deveria ser exercida sem controle do Estado, outros combatiam toda e qualquer prática profissional que fugisse aos ditames da ciência. Assim, muitos médicos, amparados na racionalidade alopática, não permitiam que fossem discutidas as bases que estruturavam, no dizer de Kuhn (1989), seu paradigma científico. Mais que isso, sua volúpia bélica impedia que outros paradigmas - como aqueles intro- duzidos pela cultura ameríndia e africana - tivessem condições de frutificar.

Da mesma forma, desqualificar e perseguir curandeiros poderia ter sido uma estratégia implementada por generalistas. Entretanto, para incitar este combate, eles não ampararam seu argumento em uma ciência reputada incontestável, como fizeram os especialistas.

Desqualificar e perseguir os curandeiros também poderia ter sido estratégia implementada por higienistas, mas o sentido da iniciativa seria distinto. Para os especialistas semelhante desqualificação visava preservar seu mercado de trabalho. Para os higienistas, a meta era fazer com que a política pública de saúde vivificasse. Assim, o médico higienista obteria prestígio e poder entre os pares e na sociedade. Todo e qualquer obstáculo que dificultasse este caminho deveria ser removido.

$\mathrm{Na}$ verdade, os médicos apresentavam distintas e simultâneas formas de inserção no mercado de trabalho, desde aquela época, no Brasil. A rotina de trabalho de muitos deles organizava-se, então, da seguinte forma: de manhã passavam visita a pacientes em hospitais filantrópicos ou públicos ou davam aulas em faculdades de medicina. No início da tarde freqüentavam alguma reunião em estabelecimento público de medicina preventiva e higiênica e, no fim da tarde e início da noite, dedicavamse à atividade em consultório particular, às visitas domiciliares ou à cirurgias, conforme o caso.

Os modelos analíticos, em geral, reduzem e simplificam a realidade social a partir da qual são construídos. Não obstante, os eixos de tensão analisados, presentes naquele contexto histórico, interferiam nos perfis profissionais médicos identificados nos anais do Congresso Nacional dos Práticos, opondo o generalismo à especialização e a prática liberal em consultório ao exercício profissional público, ou seja, assalariado.

O perfil de identidade profissional que denominamos higienista pode ser avaliado como uma das especialidades possíveis no processo de segmentação do conhecimento médico, observável desde o final do século XIX. A carreira do médico higienista integra o campo da racionalidade científica, afastando-se dos pressupostos do perfil generalista, que era regido pela arte e subjetividade na relação com o paciente. Os higienistas propugnavam uma formação especializada, voltada sobretudo para a prevenção, a educação higiênica e o diagnóstico, profilaxia, tratamento e possível cura das doenças infecto-contagiosas. Desse modo, a atividade médica não deveria se limitar nem ao conhecimento clínico abrangente nem a uma especia- 
lização que compartimentasse o corpo do indivíduo em partes dissociadas. Os higienistas introduziram a necessidade de formação especializada voltada ao atendimento das coletividades. O sentido de sua prática estava norteado para a educação higiênica e eugênica, bem como para a prevenção das doenças das coletividades.

Para alguns higienistas, a pobreza que assolava o Brasil seria determinada pela ausência de saúde. Diferindo do pensamento sanitarista predominante nos dias atuais, pensava-se, no início do século, que o trabalhador doente não teria condições plenas para o exercício de sua atividade, impedindo, em conseqüência, que a Nação atingisse o progresso almejado. Para os higienistas a doença era a causa da miséria e não a miséria a causa da doença.

O objetivo da prática profissional médica deveria ser lutar pelo progresso do país. Para atingi-lo, seria necessário sanear o indivíduo, tornando o trabalhador apto para o trabalho. Formar a humanidade, diminuir a pobreza e melhorar as condições de vida da sociedade eram os compromissos que os higienistas queriam imputar à identidade profissional médica. Como já expusemos, tanto os especialistas quanto os generalistas orientavam sua atividade para o paciente, entendido como entidade única e inconfundível. Para os médicos de perfil higienista, a cura e o bem-estar do cidadão deveriam ser obtidos em prol da humanidade e da pátria - aspecto que constitui a maior singularidade deste perfil de identidade profissional. Na história da saúde e da doença no Brasil, este elemento representa uma inflexão inédita no sentido da prática profissional médica.

Da mesma forma que os defensores dos dois ideais de prática profissional analisados anteriormente, os higienistas fizeram questão de ratificar sua identidade profissional mediante a desqualificação das demais.

Manoel José Ferreira, tinha 25 anos de idade e dois de formado quando da realização do evento. Durante sua carreira, Ferreira chegara a exercer, entre outros postos de destaque, os de Diretor de Saúde Pública, Presidente do Comitê Executivo da Organização Pan-Americana da Saúde, professor catedrático de Higiene e Presidente do Comitê Internacional de Erradicação da Malária.

Ferreira (1923:415) afirmou: "No futuro, o treinamento dos médicos deve ser mais amplamente desenvolvido sob o ponto de vista de suas relações com o público. A verdadeira função do médico deverá ser de evitar ao invés de curar a doença. Os seus deveres tendem cada vez mais à oficialização, no sentido que seus serviços de- vem ser prestados à comunhão e não exclusivamente ao indivíduo".

Quando os higienistas caracterizavam este tipo de identidade profissional como verdadeira e de futuro, parece-nos que não faziam apenas exercício de retórica. Estas palavras denotam crenças e intenções. Elas poderiam acarretar, como resultado, a abertura e/ou a ampliação dos espaços de participação dos médicos nas esferas públicas, com crescente poder, alta remuneração e incontestável prestígio que estavam sendo construídos com a organização do Departamento Nacional de Saúde Pública. Os higienistas dispunham e representavam seus interesses, lutando pelo monopólio de determinada fatia do mercado de trabalho.

Fontenelle, um dos fundadores da Sociedade Brasileira de Higiene, chefiou os postos de profilaxia rural, dedicando especial atenção ao combate à tuberculose. Durante o Congresso, defendeu a criação de uma "Escola de Higiene e Saúde Pública”. Neste sentido, Fontenelle (1923: 551) afirmou: "A atividade de higiene pública exige, hoje em dia, profissionais inteiramente especializados, (...) Impõe-se, pois, entre nós, a criação de uma Escola de Higiene e Saúde Pública, onde profissionais especializados, do país ou de fora, possam formar os técnicos indispensáveis à vasta organização sanitária que necessitamos para todo o Brasil". Sua pretensão era, portanto, obter amparo legal para a exclusividade dessa fatia de mercado.

Ao defender esta proposta, os higienistas estavam lutando pela sofisticação de sua formação e de seu conhecimento, estratégias nitidamente destinadas a ampliar seu prestígio e poder junto aos clientes, à sociedade e ao Estado. Cabe ressaltar que todos os defensores do perfil higienista atuavam, em 1922, em alguma instância de poder público vinculada à gestão dos serviços de profilaxia, educação ou ação higiênica.

No processo de afirmação profissional, os médicos identificados com o perfil generalista foram capazes de propor ao Estado os limites da gratuidade no atendimento nosocomial, já que o atendimento residencial estava restrito às pessoas com alto poder aquisitivo. Com esta limitação pretendiam garantir que semelhante clientela não se sentisse atraída por estabelecimentos públicos e continuasse a privilegiar o atendimento nos consultórios e clínicas particulares.

As vítimas, no processo de afirmação da lógica de identidade dos especialistas, foram os curandeiros, portadores de terapêutica sistematicamente desqualificada por não se enquadrar nos parâmetros da ciência alopática ofi- 
cial estabelecida. No processo de afirmação dos higienistas, os inimigos foram os generalistas e os especialistas, profissionais que viviam da clínica exercida em consultório particular, portanto, da medicina curativa, e que resistiam em fazer a denominada "notificação compulsória”.

De acordo com o que determinava o recente regulamento do Departamento Nacional de Saúde Pública, promulgado em 1920, todos os médicos deveriam notificar esta instituição logo que identificassem um paciente portador de uma das moléstias contagiosas consignadas na lei. Feita a notificação, o paciente poderia perder seu emprego e até, em caso de isolamento, o contato com a família. O período e a modalidade de isolamento variavam de acordo com a enfermidade. A readmissão às atividades ordinárias de trabalho estava condicionada à autorização formulada pelas autoridades sanitárias.

A notificação compulsória interferia, portanto, na autonomia do trabalho médico, pois obrigava o médico a adotar determinada conduta independente de sua vontade. Caso contrário estaria sujeito a uma série de sanções, multas e, inclusive, à suspensão temporária do direito ao exercício profissional.

Além disso, a notificação compulsória redimensionava o segredo profissional, afetando o cerne da relação médico-paciente baseada, segundo o Juramento Hipocrático, em sua inviolabilidade. O médico, durante consulta individual e privada, poderia identificar um paciente como portador de certa doença contagiosa se a anamnese não fosse ligeira e se a relação fosse de confiança. Na consulta o paciente oferece elementos íntimos que permitem o diagnóstico mais preciso. Obtido nessas condições, o diagnóstico pertence ao domínio do segredo profissional.

Ferir ou não a liberdade individual. Esta era uma das razões que justificavam a resistência dos generalistas e especialistas em relação ao pleno cumprimento da notificação compulsória. Para a mentalidade liberal predominante nas demais identidades médicas, nenhuma determinação legal que interferisse na autonomia do exercício da atividade seria bem-vinda.

Por sua vez, o sucesso do conjunto de medidas de caráter higiênico dependia da notificação. A partir dela, os programas do Departamento Nacional de Saúde Pública poderiam ser planejados e implementados. Passados dois anos da promulgação do Regulamento, os médicos clínicos curativos continuavam deixando de notificar. Ao menos, esta era a queixa de todos os relatores que se posicionaram a este respeito.
Henrique Autran chefiava, em 1922, o Serviço de Propaganda e Educação Sanitária do Departamento Nacional de Saúde Pública. Para Autran (1923:265), “a notificação da moléstia à autoridade sanitária representa, (...) uma condição indispensável à eficiência do serviço de saúde pública”. A preocupação dos higienistas concentrava-se mais na eficiência do sistema do que na liberdade individual do médico e sua possível contradição com os princípios hipocráticos.

Criticando os que argumentavam que a notificação compulsória feria o segredo profissional, Autran (1923:269) ainda afirmou: "A esse argumento se opõem as exigências dos altos princípios sociais, o interesse coletivo da sociedade, motivos mais que suficientes para obrigar o médico a vencer estes preconceitos e a cumprir seu dever moral e legal, qual seja, influenciar, com a notificação do doente, para que seja eficiente a ação de uma campanha, cujo fim é prestar à população serviços inestimáveis sendo como é seu escopo fazer a profilaxia de uma doença que, sobre acarretar muitos prejuízos sociais, eleva grandemente o coeficiente de mortalidade".

A retórica do interesse coletivo, nesse caso, assume peso e ocupa seu lugar. $O$ interesse individual do médico em relação a seu paciente passa a exercer papel secundário. Henrique Autran queria convencer o conjunto da categoria de que a notificação contribuiria para a eficiência do sistema e para a diminuição da mortandade.

Como vimos, a notificação compulsória poderia ser utilizada como instrumento de delação, com graves conseqüências para a vida e para o trabalho do cidadão portador de alguma dentre essas moléstias. A notificação poderia também interferir na liberdade individual do médico. Contudo, para muitos relatores, o poder de polícia que esta determinação legal representa para a vida do cidadão e do profissional não só deveria ser cumprido como ampliado.

Por que razão o médico não revela seu segredo ao Estado? Para não ser prejudicado, perdendo um elemento de sua clientela. Ao oficiar à Saúde Pública que seu paciente era portador de uma das vinte doenças notificáveis, o médico tanto infringia um princípio integrante do Juramento Hipocrático quanto descumpria o artigo 192 do Código Penal, que considerava crime revelar a qualquer pessoa um segredo obtido no exercício da profissão. Do ponto de vista estritamente jurídico, a controvérsia era portanto muito grande.

Os médicos generalistas e especialistas, inseridos de forma liberal no mercado de traba- 
lho dependiam de seus pacientes para seu sustento e sobrevivência. Se fizessem a notificação compulsória, corriam o risco de perder a confiança que os pacientes neles depositavam.

Se arrolarmos os cargos na área da Saúde Pública ocupados pelos relatores que insistiram na implementação da notificação compulsória em 1922, poderemos constatar, sem dificuldade, que estes ocupavam funções de destaque e de poder na gestão dos serviços de saúde pública na década de 20. Os higienista sustentaram coerentemente os interesse subjacentes a este perfil de identidade profissional, exigindo que a notificação compulsória fosse implementada, a despeito dos interesses particulares dos médicos clínicos.

Os médicos higienistas afirmaram sua identidade por meio da desqualificação das demais. Além disso partiram para a luta contra os médicos clínicos (generalistas e especialistas) que insistiam em não fazer a notificação compulsória.

Para encerrar este artigo gostaríamos de fazer alguns comentários de natureza teórica e metodológica. Nosso objetivo é apresentar sugestões possíveis de serem aproveitadas em estudos históricos que façam da profissão seu objeto preferencial de análise.

No nosso entender, o conceito de profissão, do ponto de vista sociológico, é válido enquanto unidade analítica, se forem levadas em conta as heterogeneidades históricas que o constituem.

Lutar pelo monopólio do conhecimento e da prática, garantir elevados índices de prestígio e remuneração, instituir padrões de comportamento em sua relação entre pares, com a sociedade e com os concorrentes, além de criar mecanismos de persuasão e de coerção que levem o cliente a sujeitar-se a sua autoridade cultural, representam algumas das estratégias pró- prias às profissões, encaradas do ponto de vista da tradição sociológica, para assegurar sua existência. Estes atributos distinguem sociologicamente as profissões das ocupações no mundo do trabalho. Tais atributos devem ser inseridos historicamente nas respectivas conjunturas em que estiverem.

Esta análise histórica deve acompanhar duas dimensões. Por um lado deve ser levada em conta a conjuntura histórica mais geral pela qual passa a sociedade em que a profissão está inserida. A profissão está submetida a uma série de injunções políticas, econômicas e culturais mais abrangentes que não dependem de sua intervenção, mas que se impõem, muitas vezes, a ela. Por outro lado, o investigador necessita atribuir importância à análise da profissão em si. Deve observar o momento histórico que a profissão passa em termos de conquista e de preservação do monopólio do conhecimento. Além disso é preciso enfatizar a historicidade das controvérsias entre identidades profissionais distintas ou concorrentes dentro de mesma configuração profissional.

Neste artigo, analisamos a profissão médica, no Brasil, no início do século XX. Naquele contexto histórico, ela estava submetida à crescente presença do Estado que interferia no mercado de trabalho médico ao promover o assalariamento. Esta tendência política mais geral não dependia da intervenção da profissão; pelo contrário, a ela se impunha. No mesmo momento, a profissão médica, em si, passava por crescente processo de especialização e de introdução da racionalidade própria da precisão técnica. As controvérsias entre identidades profissionais distintas ou concorrentes evidenciaram-se de forma contundente, mas historicamente constituídas. Caso o momento fosse diferente, outras polêmicas, tensões e heterogeneidades seriam configuradas. 


\section{Referências}

ABBOTT, A., 1988. The System of Professions: An Essay on the Division of Expert Labor. Chicago: The University of Chicago Press.

AUTRAN, H., 1923. O médico como auxiliar da administração sanitária. In: Primeiro Congresso Nacional dos Práticos, Actas e Trabalhos, pp. 263-273, Rio de Janeiro: Publicações Científicas.

BRASIL, 1921. Collecção das Leis da República dos Estados Unidos do Brasil de 1920. Volume III, Tomo I, Actos do Poder Executivo (julho a dezembro), pp. 244-484, Rio de Janeiro: Imprensa Nacional.

COUTO, M., 1923. O abuso da hospitalização gratuita. A verificação da indigência. As tarifas hospitalares módicas. In: Primeiro Congresso Nacional dos Práticos, Actas e Trabalhos, pp. 562-563, Rio de Janeiro: Publicações Científicas.

DAMAZIO, S. F., 1996. Retrato Social do Rio de Janeiro na Virada do Século. Rio de Janeiro: Eduerj.

DONNANGELO, M. C., 1975. Medicina e Sociedade. São Paulo: Pioneira.

FERREIRA, M. J., 1923. O médico como auxiliar da administração sanitária. In: Primeiro Congresso Nacional dos Práticos, Actas e Trabalhos, pp. 415420, Rio de Janeiro: Publicações Científicas.

FONTENELLE, J. P., 1923. Ensino técnico de higiene. In: Primeiro Congresso Nacional dos Práticos, $A c$ tas e Trabalhos, pp. 550-557, Rio de Janeiro: Publicações Científicas.

FREIDSON, E., 1970. Profession of Medicine. New York: Harper \& Row Publishers.

GOUBERT, J. P., 1992. Médecins d'Hier, Médecins d'Aujourd'hui. Le Cas du Docteur Laverne. Paris: $\mathrm{Pu}-$ blisud.

GUILLAUME, P., 1996. Le Rôle Social du Médecin Depuis Deux Siècles (1800-1995). Paris: Comité d'Histoire de la Securité Sociale.

HERZLICH, C., 1982. The evolution of relations between french physicians and State from 1880 to 1980. Journal of Medicine Sociology (London), 4:3.
KUHN, T., 1989. A Estrutura das Revoluções Científicas. São Paulo: Perspectiva.

LARSON, M., 1977. The Rise of Professionalism. Los Angeles: University of California Press.

LEONARD, J., 1978. Les Médecins de l'Ouest au XIXè Siècle. Paris: H. Champion.

LUZ, M. T., 1982. Medicina e Ordem Política Brasileira. Rio de Janeiro: Graal.

MACHADO, M. H., 1996. Os Médicos e sua Prática Profissional: As Metamorfoses de uma Profissão. Tese de Doutorado, Rio de Janeiro: Instituto Universitário de Pesquisa do Rio de Janeiro. (mimeo.)

MEIRELES, E., 1923. As cooperativas clínicas, seus malefícios para os médicos e para os doentes. In: Primeiro Congresso Nacional dos Práticos, Actas $e$ Trabalhos, pp. 163-172, Rio de Janeiro: Publicações Científicas.

OLIVEIRA, O., 1923. A colaboração dos práticos nas reformas do Ensino Médico. In: Primeiro Congresso Nacional dos Práticos, Actas e Trabalhos, pp. 400-407, Rio de Janeiro: Publicações Científicas.

PEREIRA, P., 1923. O regimem universitário do ensino médico. In: Primeiro Congresso Nacional dos Práticos, Actas e Trabalhos, pp. 521-532, Rio de Janeiro: Publicações Científicas.

PEREIRA NETO, A. F., 1997. Palavras, Intenções e Gestos. Os Interesses Profissionais da Elite Médica. Congresso Nacional dos Práticos (1922). Tese de Doutorado, Rio de Janeiro: Instituto de Medicina Social, Universidade do Estado do Rio de Janeiro.

PRIMEIRO CONGRESSO NACIONAL DOS PRÁTICOS, 1923. Actas e Trabalhos. Em commemoração da Independência do Brasil, setembro de 1922. Rio de Janeiro: Publicações Científicas.

SCHRAIBER, L., 1993. O Médico e seu Trabalho. Limites da Liberdade. São Paulo: Editora Hucitec.

STARR, P., 1982. The Social Transformation of American Medicine. New York: Basic Books.

WEISZ, G., 1988. Les Transformations de l'Élite Médicale en France. Actes de la Recherche en Sciences Sociales, 74:33-46. 